\title{
Efeito do Período Experimental sobre a Fermentação Ruminal e Eficiência de Síntese Microbiana em Bovinos Alimentados com Dois Níveis de Volumosos ${ }^{1}$
}

\section{Kátia Cylene Guimarães ${ }^{2}$, Antonio Ferriani Branco ${ }^{*}$, Lúcia Maria Zeoula ${ }^{3}$, Claudete Regina Alcalde $^{3}$, Fábio Luís Fregadolli ${ }^{2}$, Saul Ferreira Caldas Neto ${ }^{2}$}

\begin{abstract}
RESUMO - Os objetivos deste trabalho foram avaliar os efeitos de dois níveis de volumosos nas rações e dois períodos experimentais sobre a eficiência de síntese microbiana, a concentração ruminal de amônia, o pH ruminal, o fluxo duodenal e a digestibilidade de nitrogênio (N) em bovinos. Foram utilizados quatro novilhos, Holandês Preto e Branco, com dois anos de idade e $340 \mathrm{~kg}$ de peso vivo, implantados com cânulas ruminal e duodenal. O delineamento experimental foi um quadrado latino 4 x 4, em que os animais receberam quatro tratamentos, que consistiram de dois níveis de volumoso ( 70 e $30 \%$ ) e dois períodos experimentais ( 14 e 21 dias). Houve efeito significativo do nível de volumoso para pH e concentração de amônia no fluido ruminal. Houve efeito do período experimental sobre a ingestão de N. A eficiência de sintese microbiana aparente variou de 29,3 a 32,0 g N microbiano/kg de MODR. O pH mínimo obtido foi de 6,5 para $70 \%$ de volumoso e 6,2 para $30 \%$ de volumoso. A concentração máxima de amônia foi de 16,9 para $70 \%$ de volumoso e $18,97 \mathrm{mg} / 100 \mathrm{~mL}$ de fluido ruminal para $30 \%$ de volumoso.
\end{abstract}

Palavras-chave: amônia, nitrogênio, nível de volumoso, período experimental, $\mathrm{pH}$

\section{Effect of Experimental Period on the Ruminal Fermentation and Microbial Efficiency Synthesis in Cattle Fed Two Levels of Forage}

\begin{abstract}
The objectives of this research were to evaluate the effects of two forage levels and two experimental periods on the microbial efficiency, ruminal ammonia concentration, the ruminal pH, duodenal nitrogen $(\mathrm{N})$ flux and digestibility. Four Holstein steers, two years old and $340 \mathrm{~kg}$ of body weight, ruminally and duodenally cannulated, were used. The experimental design was a $4 \times 4$ latin square and animals received four treatments as folowing: two levels of forage (70 and 30\%) and two experimental periods (14 and 21 days). There were effects of the forage level on the ruminal ammonia concentrations and $\mathrm{pH}$. There was effect of experimental period on the intake of $\mathrm{N}$. The apparent microbial efficiency synthesis ranged from 29.3 to $32.0 \mathrm{~g}$ microbial N/ $\mathrm{kg}$ OMDR. The minimum $\mathrm{pH}$ for high forage diet (70\%) was 6.5 and for low forage diet (30\%) was 6.2. The maximum ruminal ammonia concentration of $16.9 \mathrm{mg} / 100 \mathrm{~mL}$ was obtained for the level of $70 \%$ of forage and $18.9 \mathrm{mg} / 100 \mathrm{~mL}$ of ruminal fluid to the level of $30 \%$ of forage.
\end{abstract}

Key Words: ammonia, experimental period, forage level, nitrogen, $\mathrm{pH}$

\section{Introdução}

A modificação dos níveis de volumosos na dieta de ruminantes é uma alternativa que vem sendo utilizada, com o objetivo de atingir o máximo consumo de energia e melhor aproveitamento dos alimentos fornecidos em dietas balanceadas. Vários parâmetros podem ser influenciados, com a variação nos níveis de volumosos, e suas alterações podem levar à maior ou menor eficiência no aproveitamento dos nutrientes dos alimentos, afetando, assim, a produção animal. A alteração dos níveis de volumosos na dieta pode influenciar o crescimento microbiano, em função da variação na disponibilidade de energia digestível (CLARK et al., 1992).
O crescimento microbiano pode ser afetado pela disponibilidade de carboidratos, amônia, peptídeos, aminoácidos, enxofre e ácidos graxos de cadeia ramificada (SNIFFEN et al., 1993) e por outros fatores, como a taxa de passagem, $\mathrm{pH}$, taxa de fermentação e predação dentro do rúmen (MERCHEN, 1988 e VAN SOEST, 1994).

Ao se estudar o papel da fermentação microbiana na digestão em ruminantes, a avaliação do nitrogênio disponível para absorção pelo animal torna-se indispensável. As exigências de proteína dos ruminantes são atendidas pelos aminoácidos absorvidos no intestino delgado, portanto, segundo o NRC (1985), os compostos nitrogenados não-amoniacais (NNA) no

\footnotetext{
1 Trabalho apresentado como parte da Dissertação de Mestrado do primeiro autor.

2 Estudante da Pós graduação em Zootecnia da UEM - AV. Colombo, 5790 CEP 87020-900, Maringá, PR.

3 Professor do Departamento de Zootecnia da UEM - AV. Colombo, 5790 CEP 87020-900, Maringá, PR. E.mail: afbranco@uem.br

* Bolsista pesquisador do CNPq.
} 
abomaso têm sido utilizados para avaliar o nitrogênio que chega ao intestino delgado e incluem, principalmente, nitrogênio dietético não-degradado no rúmen e nitrogênio de origem microbiana. $O$ nitrogênio não -amoniacal total do abomaso contém ainda outra fração, a proteína endógena, constituída, principalmente, de enzimas, muco e células epiteliais (LADEIRA et al., 1999).

Em situações ideais, a quantidade de aminoácidos e peptídeos, disponíveis para a absorção, deve ser igual às necessidades de aminoácidos para atender os requerimentos de mantença e produção dos ruminantes. Contudo, quando se desejam elevados níveis de produção, as necessidades protéicas aumentam e há a necessidade de maximizar a eficiência de síntese de proteína microbiana, além de evitar que parte da proteína dietética ingerida seja degradada no rúmen (BRODERICK et al., 1991).

A degradabilidade ruminal da proteína dietética leva à conversão da mesma até amônia. Quanto maior for a degradabilidade da proteína da dieta, maior será a produção de amônia ruminal e, provavelmente, maiores serão as perdas urinárias de compostos nitrogenados na forma de uréia (RUSSELL et al., 1991). VALADARES et al. (1997) verificaram que a concentração de amônia no rúmen é uma função das taxas relativas de entrada e remoção de amônia, que entra no rúmen a partir de numerosas fontes, incluindo a fermentação dos alimentos, fragmentos de células lisadas, proteína endógena, compostos nitrogenados solúveis diversos (uréia endógena, ácidos nucléicos, ácido úrico e nitrato) e excreção dos protozoários. O nitrogênio amoniacal é removido do rúmen pela incorporação à matéria microbiana que sai do rúmen, pela absorção através da parede ruminal e pelo fluido ruminal, passando para outras porções do trato digestivo.

$\mathrm{O} \mathrm{pH}$ é um fator importante na atividade proteolítica do rúmen e o valor ótimo varia entre 6 e 7 , sendo que, para grande número de microorganismos, a atividade máxima se situa em torno de 6,5 (COELHO DA SILVA e LEÃO, 1979).

Com redução moderada do $\mathrm{pH}$ ruminal, até aproximadamente 6 , a digestão da fibra decresce sem influenciar o número de organismos fibrolíticos. Porém, com redução para a faixa de 5,5 a 5,0, ocorre diminuição do número de microorganismos fibrolíticos, como também da taxa de crescimento, podendo causar inibição na digestão da fibra (HOOVER, 1986).

Normalmente, medidas de eficiência de síntese microbiana são avaliadas in vivo, por intermédio de ensaios de digestibilidade, nos quais são usados vári- os métodos para a determinação da mesma. VALADARES FILHO et al. (1990), comparando dois métodos de determinação de eficiência de síntese microbiana (2,6 diaminopimélico e bases purinas), concluíram que o método das bases purinas é adequado para estimar a produção microbiana. BRODERICK e MERCHEN (1992) recomendam a utilização das bases purinas e do ${ }^{15} \mathrm{~N}$ como indicador, ressaltando que o principal problema quanto ao uso das bases purinas é que a relação purina: $\mathrm{N}$ difere entre bactérias e protozoários, havendo ainda a necessidade de assumir que as bases purinas dietéticas são totalmente degradadas no rúmen, porém, este método pode ser utilizado pela maioria dos pesquisadores. Afirmam que o método da infusão de ${ }^{15} \mathrm{~N}$ no rúmen é o mais adequado, porém, o custo e a diferença no enriquecimento com ${ }^{15} \mathrm{~N}$ entre bactérias e protozoários são fatores limitantes. OBISPO e DEHORITY (1999) afirmam que a maior limitação para os dois procedimentos é a necessidade de amostras bacterianas do rúmen, que precisam ser representativas da população bacteriana total.

Tendo-se em vista as diferenças verificadas nos ensaios de digestibilidade quanto ao período experimental e os efeitos do nível de volumoso das dietas na produção microbiana, o objetivo deste trabalho foi avaliar a eficiência de síntese microbiana, $\mathrm{pH}$ e amônia ruminal, fluxo duodenal e a digestibilidade de nitrogênio, em dois períodos experimentais (14 e 21 dias) e dois níveis de volumoso (30 e 70\%).

\section{Material e Métodos}

O experimento foi realizado no setor de Bovinocultura de Corte da Fazenda Experimental de Iguatemi, pertencente à Universidade Estadual de Maringá, localizada no distrito de Iguatemi, no período de dezembro de 1998 a abril de 1999.

Foram utilizados quatro novilhos machos, da raça Holandês preto e branco, com dois anos de idade e $340 \mathrm{~kg}$ de peso vivo. Os animais foram implantados com cânulas ruminal e duodenal.

Os animais foram alimentados duas vezes ao dia, pela manhã $(8 \mathrm{~h})$ e à tarde $(16 \mathrm{~h})$, receberam água à vontade e foi mantido um controle higiênico/sanitário rigoroso das instalações. As baias foram lavadas duas vezes ao dia e os bebedouros, semanalmente, assegurando assim o fornecimento de água de boa qualidade. Os animais foram pesados no início de cada período experimental, com o objetivo de ajustar o consumo de matéria seca. 
882 Rev. bras. zootec.

Os animais permaneceram em baias individuais com $10 \mathrm{~m}^{2}$ de área útil, com piso concretado e $50 \%$ da área coberta. As baias eram providas de comedouro individual coberto e bebedouro coletivo para cada duas baias.

Os períodos experimentais foram de 14 ou 21 dias, com três dias de coleta de amostras (fluido ruminal, conteúdo ruminal e digesta duodenal), no final de cada um dos períodos

As dietas (Tabela 1) foram calculadas para atender 1,3 vezes a exigência de energia de mantença e os tratamentos foram avaliados em esquema fatorial 2 x 2, sendo dois níveis de volumosos (30 e 70\%) e dois períodos experimentais (14 e 21 dias).

A concentração estimada de energia metabolizável e de proteína bruta das rações foi: $\mathrm{AV}=2,23 \mathrm{Mcal}$ de $\mathrm{EM} / \mathrm{kg}$ de MS e $12,5 \%$ de $\mathrm{PB}$ e BV $=2,58$ Mcal de $\mathrm{EM} / \mathrm{kg}$ de $\mathrm{MS}$ e $13,3 \%$ de PB.

O óxido de cromo foi utilizado como indicador para determinar o fluxo da digesta, sendo o mesmo colocado por meio de cânula diretamente no rúmen, em duas doses diárias de 5,0 g, durante todo o período experimental. O indicador foi fornecido nos horários de alimentação.

Para determinar a partição do fluxo duodenal do $\mathrm{N}$, foram coletadas amostras da digesta duodenal $(200 \mathrm{~mL})$. As amostras de digesta duodenal foram acondicionadas em sacos plásticos, devidamente etiquetados e congeladas para posterior

Tabela 1 - Proporção dos ingredientes usados nas dietas (\% MS)

Table 1 - Ingredient proportion used in the diets (\% DM)

\begin{tabular}{|c|c|c|}
\hline \multirow[b]{2}{*}{$\begin{array}{l}\text { Ingrediente } \\
\text { Ingredient }\end{array}$} & \multicolumn{2}{|c|}{$\begin{array}{c}\text { Dieta } \\
\text { Diet }\end{array}$} \\
\hline & $\mathrm{AV}^{1}$ & $\mathrm{BV}^{2}$ \\
\hline $\begin{array}{l}\text { Casca de mandioca } \\
\text { Cassava hulls }\end{array}$ & 7,00 & 17,00 \\
\hline $\begin{array}{l}\text { Polpa de citrus } \\
\text { Citrus pulp }\end{array}$ & 10,00 & 20,00 \\
\hline $\begin{array}{l}\text { Farelo de soja } \\
\text { Soybean meal }\end{array}$ & 7,10 & 15,80 \\
\hline $\begin{array}{l}\text { Raspa de mandioca } \\
\text { Cassava root }\end{array}$ & 5,40 & 17,00 \\
\hline $\begin{array}{l}\text { Uréia } \\
\text { Urea }\end{array}$ & 0,50 & 0,20 \\
\hline $\begin{array}{l}\text { Feno de Tifton } \\
\text { Tifton hay }\end{array}$ & 70,00 & 30,00 \\
\hline $\begin{array}{l}{ }^{1} \mathrm{AV}=\text { Dieta com alta cc } \\
\text { diet }[70 \%]) . \\
{ }^{2} \mathrm{BV}=\text { Dieta com baixa c c } \\
\text { diet [30\%]). } \\
{ }^{3} \text { Cynodon spp. }\end{array}$ & a de v & $\begin{array}{l}\text { High forage } \\
\text { (Low forage }\end{array}$ \\
\hline
\end{tabular}

processamento e análises. As amostras de digesta duodenal foram coletadas durante três dias, com intervalos de 6 horas e incremento de 2 horas de um dia para o outro, totalizando 12 amostras por animal e tratamento (BRANCO et al., 1999).

As amostras de digesta duodenal foram secas em estufa, com circulação forçada de ar (MA035 MARCONE ${ }^{\circledR}$ ) a $55^{\circ} \mathrm{C}$ por 72 horas, moídas, individualmente, em moínhos de faca $\left(\mathrm{MARCONE}^{\circledR}\right)$, em peneira com crivo de $1 \mathrm{~mm}$, e misturadas em quantidades iguais, com base no peso seco, para formar amostras compostas por animal e tratamento.

As sobras de alimento no comedouro foram recolhidas, diariamente, pesadas e amostradas, sendo, então, congeladas para posterior análise. As mesmas foram submetidas ao procedimento descrito anteriormente, para o preparo das amostras de digesta duodenal. O concentrado da dieta foi amostrado, semanalmente, formando-se amostras compostas e o feno foi amostrado, diariamente, formando, posteriormente, amostras compostas, para cada tratamento.

As amostras dos alimentos, das sobras no comedouro e da digesta duodenal foram analisadas para teores de MS, MO e N, utilizando os métodos descritos por SILVA (1990).

O teor de cromo nas amostras de digesta duodenal foi determinado por espectrofotometria de absorção atômica, conforme técnica descrita por WILLIANS et al. (1962), e usado juntamente com a concentração de nutrientes, para determinar o fluxo de $\mathrm{N}$ para o duodeno.

Para determinar o pH e a concentração de amônia no líquido ruminal, foram coletadas amostras do fluído ruminal (cerca de $100 \mathrm{~mL}$ ), via cânula ruminal, nos tempos $0 ; 2 ; 4 ; 6 ; 8 ; 10 ; 12 ; 16$ e 24 horas após o início da fase de coleta, em cada período experimental. O tempo zero corresponde à amostra coletada imediatamente antes da primeira refeição, e o tempo 10 , onde ocorreu simultâneamente ao fornecimento da segunda refeição (dezesseis horas).

$\mathrm{O}$ pH foi medido imediatamente após a coleta e $50 \mathrm{~mL}$ de fluído ruminal foram acidificados com $1 \mathrm{~mL}$ de ácido sulfúrico $(1: 1)$ e armazenados a $-20^{\circ} \mathrm{C}$, para posterior análise de $\mathrm{NH}_{3}$.

A dosagem de amônia nas amostras de líquido ruminal foi determinada pela técnica de Ferner (1965) modificada por VIEIRA (1980).

Para determinação da eficiência de síntese microbiana, foram coletados $1,5 \mathrm{~kg}$ de conteúdo ruminal no último dia de cada período e misturados a $500 \mathrm{~mL}$ de solução salina $0,9 \%(\mathrm{NaCl})$. A mistura 
GUIMARÃES et al.

foi homogeneizada em liqüidificador, coada com um pano dobrado quatro vezes e o filtrado armazenado a $-20^{\circ} \mathrm{C}$ para ser processado de acordo com CECAVA et al. (1990).

A concentração de purinas nas bactérias do rúmen e na digesta duodenal foi determinada pelo procedimento descrito por USHIDA et al. (1985), com algumas modificações propostas por BOHNERT et al. (1998).

O fluxo total de $\mathrm{N}$ microbiano para o duodeno (g/dia) foi estimado pela divisão da razão $\mathrm{N}$ : purinas bactéria pela razão $\mathrm{N}$ : purinas digesta duodenal e multiplicando este quociente pelo fluxo total individual de $\mathrm{N}$.

A eficiência de síntese microbiana foi também expressa em g de $\mathrm{N}$ microbiano/kg de matéria orgânica (MO) verdadeira fermentada no rúmen que, por sua vez, foi calculada pela equação = ingestão de MO (g/dia) - [MO duodenal (g/dia) MO microbiana (g/dia)].

O delineamento experimental utilizado foi o quadrado latino $4 \times 4$, no qual foram avaliados quatro tratamentos. Os dados foram interpretados por uma análise de variância, adotando-se 5\% de probabilidade e utilizando-se o procedimento ANOVA do SAS (1989).

Para os valores observados de $\mathrm{pH}$ e concentração de $\mathrm{N}-\mathrm{NH}_{3}$ no líquido ruminal, os tratamentos foram dispostos em esquema de parcelas subdivididas, em que as parcelas foram o período experimental, enquanto o nível de volumoso e os tempos de amostragem, as subparcelas.

Foi utilizada a análise de regressão para as concentrações de $\mathrm{pH}$ e $\mathrm{N}-\mathrm{NH}_{3}$ do líquido ruminal em função do tempo, após a alimentação da manhã $(0,2$, 4, 6 e 8 horas), para cada tratamento.

\section{Resultados e Discussão}

Os valores obtidos com relação à ingestão de nitrogênio (N) são mostrados na Tabela 2. A ingestão de $\mathrm{N}$ foi $2,5 \%$ superior para o período experimental de 14 dias em dietas com $70 \%$ de volumoso.

Tabela 2 - Ingestão média diária (ING), fluxo duodenal (FD), digestão ruminal (DR) e coeficiente de digestibilidade aparente ruminal (CDAR) de nitrogênio, fluxo duodenal de nitrogênio bacteriano (FDNB), fluxo duodenal de nitrogênio não bacteriano (FDNNB), eficiência microbiana aparente (EMA), eficiência microbiana verdadeira (EMV), valores de $\mathrm{pH}$ e $\mathrm{N}-\mathrm{NH}_{3}$ ruminal

Table 2 - Average daily intake (INT), duodenal flow (DF), ruminal digestion (RD), and coefficient of apparent ruminal digestibility (CARD) of nitrogen, duodenal flow of bacterial nitrogen (DFBN), duodenal flow of non bacterial nitrogen (DFNBN), apparent microbial efficiency (AME), true microbial efficiency (TME), ruminal $\mathrm{pH}$ and $\mathrm{N}-\mathrm{NH}_{3}$ values

\begin{tabular}{|c|c|c|c|c|c|}
\hline \multirow{3}{*}{$\begin{array}{l}\text { Item } \\
\text { Item }\end{array}$} & \multicolumn{4}{|c|}{$\begin{array}{l}\text { Efeito principal } \\
\text { Principal effect }\end{array}$} & \multirow[b]{3}{*}{$\begin{array}{l}\text { Erro-padrão } \\
\text { da média } \\
\text { Standard error } \\
\text { of the mean }\end{array}$} \\
\hline & \multicolumn{2}{|c|}{$\begin{array}{l}\text { Nível de volumoso, \% } \\
\text { Forage level, } \%\end{array}$} & \multicolumn{2}{|c|}{$\begin{array}{l}\text { Período experimental, dias } \\
\text { Experimental period, days }\end{array}$} & \\
\hline & 70 & 30 & 14 & 21 & \\
\hline $\begin{array}{l}\text { ING (g/dia) } \\
I N T\end{array}$ & 166,77 & $156,61^{* *}$ & 163,57 & $159,81^{*}$ & 1,12 \\
\hline $\begin{array}{l}\mathrm{FD}(\mathrm{g} / \mathrm{dia}) \\
D F\end{array}$ & 124,71 & 116,35 & 120,63 & 120,43 & 4,69 \\
\hline $\begin{array}{l}\text { FDNB (g/dia) } \\
D F B N\end{array}$ & 100,60 & 93,03 & 95,72 & 97,92 & 5,07 \\
\hline $\begin{array}{l}\text { FDNNB (g/dia) } \\
D F N B N\end{array}$ & 24,11 & 23,32 & 24,91 & 22,52 & 5,11 \\
\hline $\begin{array}{l}\text { EMA (g N/kg MODR) } \\
A M E\end{array}$ & 29,30 & 32,02 & 30,73 & 30,59 & 2,22 \\
\hline $\begin{array}{l}\text { EMV (g N/kg MODR) } \\
T M V\end{array}$ & 20,56 & 21,74 & 21,03 & 21,27 & 0,84 \\
\hline $\begin{array}{l}\mathrm{DR}(\mathrm{g} / \mathrm{dia}) \\
R D\end{array}$ & 42,06 & 40,25 & 42,94 & 39,37 & 4,69 \\
\hline $\begin{array}{l}\text { CDAR }(\%) \\
C A R D\end{array}$ & 25,22 & 25,70 & 26,25 & 24,63 & 2,88 \\
\hline $\begin{array}{l}\mathrm{pH} \\
\mathrm{N}-\mathrm{NH}_{3}(\mathrm{mg} / 100 \mathrm{~mL})\end{array}$ & $\begin{array}{r}6,47 \\
11,09\end{array}$ & $\begin{array}{r}6,31^{* *} \\
14,20^{* *}\end{array}$ & $\begin{array}{r}6,42 \\
12,29\end{array}$ & $\begin{array}{r}6,35 \\
13,00\end{array}$ & $\begin{array}{l}0,14 \\
3,13\end{array}$ \\
\hline
\end{tabular}

$\mathrm{e}^{* *}$ significativo a 5 e $1 \%$ respectivamente (significant at 5 and $1 \%$, respectively). 
884 Rev. bras. zootec.

BERCHIELLI et al. (1995), avaliando três níveis de volumosos (40, 60 e $80 \%$ ), observaram que a ingestão de $\mathrm{N}$ foi semelhante entre os níveis de 40 e $60 \%$ de volumoso, porém maiores que a dieta com $80 \%$ de volumoso. CECAVA et al. (1991) e LADEIRA et al. (1999) observaram que a ingestão de $\mathrm{N}$ foi maior, quando se forneceu baixo nível de volumoso, o que difere do comportamento observado neste trabalho.

O fluxo duodenal de nitrogênio não sofreu efeito ( $\mathrm{P}>0,05)$ do nível de volumoso da dieta e do período experimental (Tabela 2). O fluxo duodenal de nitrogênio bacteriano e de nitrogênio não bacteriano apresentou o mesmo comportamento que o fluxo duodenal de nitrogênio. MERCHEN et al. (1986) observaram interações significativas entre ingestão e nível de forragem (25 e 75\%) para o fluxo duodenal de $\mathrm{N}$ bacteriano. Os mesmos autores verificaram maior fluxo de $\mathrm{N}$ bacteriano para o duodeno de ovinos recebendo dietas com $25 \%$ de forragem.

BERCHIELLI et al. (1995) obtiveram efeito linear positivo para o fluxo de compostos nitrogenados não amoniacais, com níveis crescentes de concentrado, entretanto, quando os mesmos foram expressos como porcentagem do $\mathrm{N}$ ingerido, não houve diferença significativa para os níveis de concentrado na dieta.

Ao avaliarem diferentes níveis de concentrado em dietas de bovinos, CARVALHO et al. (1997) verificaram que as quantidades de compostos nitrogenados totais e os compostos nitrogenados microbianos presentes no abomaso não foram afetados pelos níveis de concentrado nas rações.

A digestão ruminal dos compostos nitrogenados $(\mathrm{N})$ ( $\mathrm{g} /$ dia) não sofreu efeito $(\mathrm{P}>0,05)$ da interação período experimental e diferentes níveis de volumosos, do nível de volumoso e do período experimental (Tabela 2).

Não houve efeito $(\mathrm{P}>0,05)$ do período experimental nos diferentes níveis de volumosos, do período experimental e do nível de volumoso (Tabela 2) sobre o coeficiente de digestibilidade ruminal do nitrogênio.

A composição das bactérias isoladas é mostrada na Tabela 3.

Não houve efeito $(\mathrm{P}>0,05)$ do nível de volumoso e do período experimental sobre os teores de matéria seca (MS), matéria orgânica (MO) e nitrogênio (N) bacteriano (Tabela 3). Os valores de MS obtidos de 91,5 a 92,6\% foram próximos à média encontrada por VALADARES FILHO (1995), de 89,2\%, e encontram-se na faixa de variação $(81,1$ a $95,7 \%)$ citada pelo mesmo autor.

Os valores de MO estão próximos da média obtida por RABELLO et al. (1996), que foi de 87,3\%.

LADEIRA et al. (1999), avaliando níveis de concentrado $(25 ; 37,5 ; 50 ; 62,5$ e $75 \%)$, obtiveram variação no teor de MO de 91,2 a $94,1 \%$, portanto, próximo aos valores encontrados neste trabalho. Alguns autores como CLARK et al. (1992) e VALADARES FILHO (1995) têm encontrado grande variação para os teores de MO e o último autor afirma que, possivelmente, a contaminação com solução salina, durante o processo de isolamento das bactérias, seja responsável pela grande oscilação encontrada.

Quanto ao teor de $\mathrm{N}$ bacteriano, os valores obtidos variaram de 5,8 a 6,0\%, sendo os mesmos inferiores aos encontrados por RABELLO et al. (1996), CARVALHO et al. (1997), VALADARES et al. (1997) e LADEIRA et al. (1999), porém se encontra dentro da faixa de variação citada por VALADARES FILHO (1995), que é de 5,2 a $8,7 \%$, e da faixa citada por VAN SOEST (1994), de 5,0 a 12,4\%.

Tabela 3 - Teores de matéria seca (MS), matéria orgânica (MO) e nitrogênio $(N)$ das bactérias ruminais Table 3 - Levels of dry matter (DM), organic matter (OM) and nitrogen (N) of mixed rumen bacteria

\begin{tabular}{|c|c|c|c|c|c|}
\hline \multirow{3}{*}{$\begin{array}{l}\text { Item } \\
\text { Item }\end{array}$} & \multicolumn{4}{|c|}{$\begin{array}{l}\text { Efeito principal } \\
\text { Principal effect }\end{array}$} & \multirow[b]{3}{*}{$\begin{array}{l}\text { Erro-padrão } \\
\text { da média } \\
\text { Standard error } \\
\text { of the mean }\end{array}$} \\
\hline & \multicolumn{2}{|c|}{$\begin{array}{c}\text { Nível de volumoso, \% } \\
\text { Forage level, \% }\end{array}$} & \multicolumn{2}{|c|}{$\begin{array}{l}\text { Período experimental, dias } \\
\text { Experimental period, days }\end{array}$} & \\
\hline & 70 & 30 & 14 & 21 & \\
\hline$\overline{M S(\%)}$ & 91,89 & 92,09 & 91,70 & 92,28 & 0,43 \\
\hline $\begin{array}{l}D M \\
\mathrm{MO}(\%) \\
O M\end{array}$ & 83,71 & 86,57 & 86,04 & 84,24 & 2,35 \\
\hline $\mathrm{N}(\%)$ & 5,91 & 5,99 & 5,93 & 5,98 & 0,29 \\
\hline
\end{tabular}


A eficiência de síntese microbiana aparente (Tabela 2), expressa em $\mathrm{g} \mathrm{N}$ bac./kg de MODR (gramas de nitrogênio bacteriano por kilograma de matéria orgânica degradada no rúmen), variou de 29,3 a 32,0, quando se considerou nível de volumoso, e de 30,6 a 30,7 , quando se considerou período experimental, sendo que não se observaram diferenças significativas $(\mathrm{P}>0,05)$, em ambos os casos, ao se considerar o período experimental nos diferentes níveis de volumoso. Ao se avaliar a eficiência microbiana verdadeira também expressa em $\mathrm{g} \mathrm{N}$ bac./ kg de MODR, observou-se o mesmo comportamento que para a aparente.

O NRC (1984) cita algumas razões para a menor produção de $\mathrm{N}$ pelas bactérias em dietas com altos níveis de concentrado: inadequada quantidade de proteína degradada no rúmen, alta produção de ácido láctico, resultando em menor fonte de ATP, redução no $\mathrm{pH}$ ruminal, aumento dos protozoários e do consumo de bactérias pelos protozoários e redução na salivação.

LADEIRA et al. (1999) encontraram efeito quadrático para a eficiência de síntese microbiana em função do nível de volumoso, estimando eficiência máxima de 28,6 g N bac./kg de MODR para o nível de 48,68\% de concentrado, e obtiveram, para os níveis de 25 e $75 \%$ de concentrado, os valores de eficiência microbiana de 23,2 $\mathrm{g} \mathrm{N}$ bac./kg de MODR. Este valor está abaixo dos obtidos no presente trabalho, com 30 e $70 \%$ de concentrado.

MERCHEN et al. (1986) e CECAVA et al. (1991) encontraram efeito do nível energético na eficiência microbiana. Outros autores (CARVALHO et al., 1997; CARDOSO et al., 1999; CHAVES DIAS et al., 1999) verificaram que a eficiência microbiana não foi influenciada pelos níveis de concentrado e TIBO et al. (1999) encontraram efeito quadrático da eficiência microbiana pelos níveis de concentrado da dieta, porém, o valor máximo foi de $41,2 \mathrm{~g} \mathrm{~N}$ bac./kg de MODR.

Os valores de $\mathrm{pH}$, entre tratamentos e horários, variaram de 5,6 a 6,8. O comportamento entre os tratamentos com alto volumoso foi semelhantes, bem como entre os tratamentos com baixo volumoso.

$\mathrm{O} \mathrm{pH}$ foi maior $(\mathrm{P}<0,01)$ para a dieta com $70 \%$ de volumoso (Tabela 2), devido à maior ingestão que ocorreu com esta dieta. O período experimental não influenciou $(\mathrm{P}>0,05)$ o $\mathrm{pH}$, entretanto, ao se avaliar a interação do período experimental nos diferentes níveis de volumoso, observou-se que o $\mathrm{pH}$ do período experimental de 14 dias foi maior $(\mathrm{P}<0,05)$ que $\mathrm{o}$ período experimental de 21 dias para a dieta com
$30 \%$ de volumoso.

As regressões obtidas ao se relacionar $\mathrm{pH}$ com o tempo após alimentação (utilizando-se somente as leituras feitas até as 8 horas), nos diferentes níveis de volumoso, são mostradas na Tabela 4.

Os valores de $\mathrm{pH}$ do líquido ruminal sofreram efeito quadrático $(\mathrm{P}<0,01)$ do tempo pós-alimentação, sendo que o valor mínimo para a dieta com $70 \%$ de volumoso foi de 6,5 com o tempo de 7,5 horas e, para a ração com $30 \%$, de 6,2 com o tempo de 5,6 horas (Figura 1). O valor 6,5 está acima do encontrado por CARDOSO et al. (1999), que foi de 6,2 para dieta com $75 \%$ de volumoso, mas o valor de 6,2 é semelhante ao valor obtido pelos mesmos autores.

$\mathrm{O} \mathrm{pH}$ da dieta com baixo nível de volumoso foi menor $(\mathrm{P}<0,01)$, bem como o tempo em horas, para atingir o valor mínimo de $\mathrm{pH}$, sendo este comportamento semelhante ao observado por LANA et al. (1998). TIBO et al. (1999) e CHAVES DIAS et al. (1999) obtiveram efeito linear do $\mathrm{pH}$, em função da hora.

MERCHEN et al. (1986) afirmaram que níveis mais elevados de concentrado na dieta resultam em decréscimo no $\mathrm{pH}$ ruminal, devido à rápida hidrólise e fermentação dos carboidratos não-estruturais e, segundo RIBEIRO et al (1999), valores de $\mathrm{pH}$ abaixo de 5,5 prejudicam os microrganismos celulolíticos, portanto, os valores encontrados nesta pesquisa estão dentro da faixa considerada favorável à digestão da fibra.

Observou-se que a concentração de amônia foi maior $(\mathrm{P}<0,01)$ para a dieta com $30 \%$ de forragem (Tabela 2), entretanto, não houve efeito $(\mathrm{P}>0,05) \mathrm{do}$ período experimental nos diferentes níveis de volumoso (Tabela 2), o que difere de MERCHEN et al. (1986), que não observaram efeito do nível de forragem sobre a concentração de amônia.

Tabela 4 - Equações de regressão para pH e $\mathrm{N}^{-\mathrm{NH}_{3}}$, em função do tempo de coleta

Table 4 - Regression equations of $\mathrm{pH}$ and $\mathrm{N}-\mathrm{NH}_{3}$, in function of sampling time

\begin{tabular}{lccc}
\hline Item & $\begin{array}{c}\text { Forragem } \\
\text { Forage } \\
(\%)\end{array}$ & $\begin{array}{c}\text { Regressão } \\
\text { Regression }\end{array}$ & $\mathrm{r}^{2}$ \\
\hline $\mathrm{P}_{\mathrm{H}}$ & 70 & $\mathrm{Y}=6,7245-0,061973 * \mathrm{X}+0,0041294 * \mathrm{X}^{2}$ & 0,28 \\
$\mathrm{P}$ & 30 & $\mathrm{Y}=6,7713-0,183268 * \mathrm{X}+0,0162053 * \mathrm{X}^{2}$ & 0,53 \\
$\mathrm{~N}-\mathrm{NH}_{3}$ & 70 & $\mathrm{Y}=12,5048+3,07844 * \mathrm{X}-0,536639 * \mathrm{X}^{2}$ & 0,59 \\
$\mathrm{~N}_{3} \mathrm{NH}_{3}$ & 30 & $\mathrm{Y}=19,7483+1,17421 * \mathrm{X}-0,392803 * \mathrm{X}^{2}$ & 0,54 \\
\hline
\end{tabular}


As equações de regressão obtidas, quando se avaliaram as concentrações de amônia $(\mathrm{mg} / 100 \mathrm{~mL}$ de fluído ruminal), em função da hora de coleta e nos diferentes níveis de volumoso, são mostradas na Tabela 4.

Para a dieta com $70 \%$ de volumoso foi estimada a máxima concentração de $16,9 \mathrm{mg} / 100 \mathrm{~mL}$ ao tempo de coleta de 2,9 horas, enquanto, para a dieta com $30 \%$ de volumoso, estimou-se a máxima concentração de 18,9 mg/100 mL a 1,5 horas (Figura 2).

LADEIRA et al. (1999), avaliando níveis de concentrado ( 25 a $75 \%$ ) em dietas de bovinos, verificaram que a concentração máxima de amônia no rúmen ocorreu 3,2 horas após alimentação, cujos valores obtidos variaram de 20,2 a 30,6 mg/100 mL, os quais foram superiores aos encontrados neste

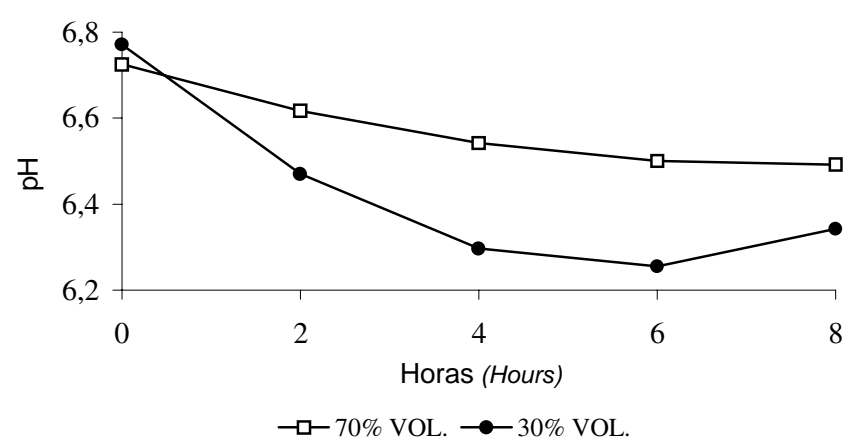

Figura 1 - pH ruminal para os diferentes níveis de volumosos. Figure 1 - Ruminal $\mathrm{pH}$ for different forage levels.

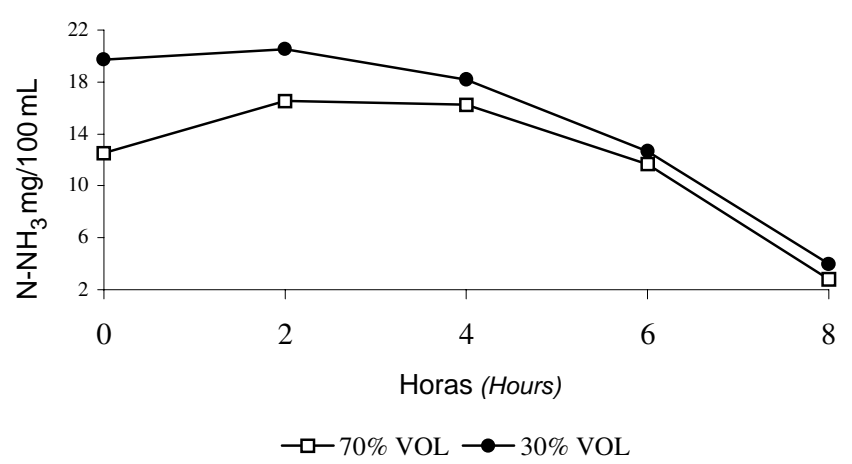

Figura 2 - Concentração de $\mathrm{N}-\mathrm{NH}_{3}$ no fluido ruminal para os diferentes níveis de volumosos.

Figure 2 - Ruminal fluid $\mathrm{N}-\mathrm{NH}_{3}$ for different forage levels. trabalho. Por outro lado, DIAS et al. (1999), também avaliando níveis de concentrado, obtiveram valores de concentração máxima de 12,5 a 21,9 mg N-NH $3 / 100 \mathrm{~mL}$, o que está próximo ao encontrado neste trabalho.

\section{Conclusões}

Não houve efeito do período experimental para os parâmetros avaliados.

A composição química bacteriana e eficiência de síntese microbiana não foram afetadas pelos níveis de volumosos avaliados.

Portanto, nas condições em que o experimento foi realizado, ou seja, usando feno como fonte de volumoso, o período experimental de 14 dias permitiu a completa adaptação dos animais às dietas e, portanto, a utilização deste período experimental é perfeitamente viável.

\section{Referências Bibliográficas}

AGRICULTURAL AND FOOD RESEARCH COUNCIL AFRC. 1993. Energy and protein requeriments of ruminants. Wallington, UK. CAB international. 159p.

AGRICULTURAL RESEARCH COUNCIL - ARC. 1984. Report of the protein group of the Agricultural Research Council Working party, on the nutrient requeriment of ruminants. London: Commonwealth Agricultural Bureaux. 45p.

BERCHIELLI, T.T., RODRIGUEZ, N.M., GONÇALVES, S.L.C. et al. 1995. Fluxo de nitrogênio duodenal e degradabilidade ruminal do nitrogênio da dieta estimado por meio de três marcadores microbianos. R. Soc. Bras. Zootec., 24(5): 810-819.

BOHNERT, D.W., LARSON, B.I., BAUER, M.L. et al. 1998. Nutritional Evaluation of poultry by-product meal as a protein source for ruminants: Effects on performance and nutrient flow and disappearance in steers. J. Anim. Sci., 76:2474-2484.

BRANCO, A.F., HARMON, D.L., BOHNERT, D.W. et al. 1999. Estimating true digestibility of nonstructural carbohydrates in the small intestine of steers. J. Anim. Sci., 77:1889-1895.

BRODERICK, G.A., WALLACE, R.J., ORSKOV, E.R. 1991. Control of rate and extent of protein degradation. In: TSUDA, T., SASAKI, Y., KAWASHIMA, R. (Eds.) Physiological aspects of digestion and metabolism in ruminants. New York: Academic Press. p.542-592.

BRODERICK, G.A., MERCHEN, N.R. 1992. Markers for quantifying microbial protein synthesis in the rumen. J. Dairy Sci., 75(9):2618-2632.

CARDOSO, R.C., VALADARES FILHO, S.C., COELHO DA SILVA, J.F. et al. Influência dos níveis de concentrado sobre a síntese microbiana, $\mathrm{pH}$ e concentração de amônia ruminal, em novilhos F1 limousin x nelore. In: REUNIÃO ANUAL DA SOCIEDADE BRASILEIRA DE ZOOTECNIA, 36, 1999, Porto Alegre. Anais... Porto Alegre: SBZ, 1999. p. 258.

CARVALHO, A.U., VALADARES FILHO, S.C., COELHO DA SILVA, J.F. et al. 1997. Níveis de concentrado em dietas de Zebuínos. Eficiência microbiana e população de 
protozoários ruminais. R. Bras. Zootec., 26(5):1007-1015.

CECAVA, M.J., MERCHEN, N.R., GAY, L.C. et al. 1990. Composition of ruminal bacteria harvested from steers as influenced by dietary energy level, feeding frequency and isolation techniques. J. Dairy Sci., 73(9):2480-2488.

CECAVA, M.J., MERCHEN, N.R., BERGER, L.L. et al. 1991. Effects of dietary energy level and protein source on nutrient digestion and ruminal nitrogen metabolism in steers. J. Anim. Sci., 69:2230-2243.

CLARK, J.H., KLUSMEYER, T.H. CAMERON, M.R. 1992. Microbial protein synthesis and flows of nitrogen fractions to the duodenum of dairy cows. J. Dairy Sci., 75(8):2304-2323.

COELHO DA SILVA, J.F., LEÃO, M.I. 1979. Fundamentos de nutrição de ruminantes. Piracicaba: Editora Livroceres. 380p.

DIAS, H.L.C., VALADARES FILHO, S.C., COELHO DA SILVA, J.F. et al. Eficiência de síntese microbiana, pH e concentrações ruminais de amônia em novilhos F1 limousin $\mathrm{x}$ nelore alimentados com cinco níveis de concentrado. In: REUNIÃO ANUAL DA SOCIEDADE BRASILEIRA DE ZOOTECNIA, 36, 1999, Porto Alegre. Anais... Porto Alegre: SBZ, 1999. p.258.

HOOVER, W.H. 1986. Chemical factors involved en ruminal fiber digestion. J. Dairy Sci., 69(10):2755-2766.

LADEIRA, M.M., VALADARES FILHO, S.C., LEÃO, M.I. 1999. Eficiência microbiana, concentração de amônia, pH ruminal e perdas nitrogenadas endógenas, em novilhos nelore. Rev. bras. zootec., 28(2):404-411.

LANA, R.P., RUSSEL, J.B., AMBURGH, M.E.V. 1998. The role of $\mathrm{pH}$ in regulating ruminal methane and ammonia production. J. Anim. Sci., 76:2190-2156.

MERCHEN, N.R., FIRKINS, J.L., BERGER, L.L., 1986. Effect of intake and forage level on ruminal turnover rates, bacterial protein synthesis and duodenal amino acid flows in sheep. J. Anim. Sci., 62:216-225.

MERCHEN, N.R. 1988. Digestion, absorption and excretion in ruminants. In: CHURCH, D.C. (Ed.) The ruminant animal: digestive physiology and nutrition. Prentice hall: Englewood cliffs, 2.ed. p.172-201.

NATIONAL RESEARCH COUNCIL - NRC. 1984. Nutrient requeriment of beef cattle. 6.ed. Washington D.C. 89p.

NATIONAL RESEARCH COUNCIL - NRC. 1985. Ruminant nitrogen usage. Washington D.C. 138p.

OBISPO, N.E., DEHORITY, B.A. 1999. Feasibility of using total purine as a marker for ruminal bacteria. J. Anim. Sci., 77:3084-3095.

RABELLO, T.G., VALADARES FILHO, S.C., COELHO DA SILVA, J.F. et al. 1996. Grão de soja moído na alimentação de vacas em lactação. III- Eficiência microbiana, amônia e pH. R. Soc. Bras. Zootec., 25(2):270-281.

RIBEIRO, K.G., GARCIA, R., PEREIRA, O.G. et al. Concentração de amônia, $\mathrm{pH}$ ruminal e taxa de passagem em bovinos recebendo dietas com feno de tifton 85 de diferentes idades. In: REUNIÃO ANUAL DA SOCIEDADE BRASILEIRA DE ZOOTECNIA, 36, 1999, Porto Alegre. Anais... Porto Alegre: SBZ, 1999. p.264.

RUSSELL, J.B., ONODERA, R., HINO, T. 1991. Ruminal protein fermentation: new perspectives on previous contradictions. In: TSUDA, T., SASAKI, Y., KAWASHIMA,
R. (Eds.) Physiological aspects of digestion and metabolism in ruminants. New York, Academic Press. p.682-697.

SAS INSTITUTE INC., SAS/STAT., 1989. Version 6, 4.ed., Cary, NC: SAS institute Inc., 943p. (User's guide)

SILVA, D.J. 1990. Análise de alimentos. 2.ed. Viçosa: UFV. $166 \mathrm{p}$.

SNIFFEN, C.J., BEVERLY, R.W., MOONEY, C.S. et al. 1993. Nutrient requeriments versus supply in the dairy cow: strategies to account for variability. J. Dairy Sci., 76(10):3160-3178.

TIBO, G.C., VALADARES FILHO, S.C., COELHO DA SILVA, J.F. et al. Níveis de concentrado na dieta de novilhos F1 simental x nelore.3- Eficiência microbiana e parâmetros ruminais. In: REUNIÃO ANUAL DA SOCIEDADE BRASILEIRA DE ZOOTECNIA, 36, 1999, Porto Alegre. Anais... Porto Alegre: SBZ, 1999. p.259.

USHIDA, K., LASSALAS, B., JOUANK, J.P. 1985 Determination of assay parameters for RNA analysis in bacterial and duodenal samples by spectrophotometry. Influence of sample treatment and preservation. Reprod. Nutr. Dev., 25:1037-1044.

VALADARES, R.F.D., CONÇALVES, L.C., SAMPAIO, I.B. et al. 1997. Níveis de proteína em dietas de bovinos. 3-pH, amônia e eficiência microbiana. R. Bras. Zootec., 26(6):1264-1269.

VALADARES FILHO, S.C., COELHO DA SILVA, J.F., LEÃO, M.I. et al. 1990. Eficiência de síntese microbiana em novilhos holandeses, nelores e búfalos mestiços, obtida por diferentes métodos. R. Soc. Bras. Zootec., 19(5):424-440.

VALADARES FILHO, S.C. Eficiência de síntese de proteína microbiana, degradação ruminal e digestibilidade intestinal da proteína bruta, em bovinos. In: SIMPÓSIO INTERNACIONAL SOBRE EXIGÊNCIAS NUTRICIONAIS DE RUMINANTES, 1995, Viçosa. Anais... Viçosa: UFV, 1995. p.355-388.

VAN SOEST, P.J. 1994. Nutritional ecology of the ruminant. 2.ed. London: Cornell University. 476p.

VIEIRA, P.F. Efeito do formaldeído na proteção de proteínas e lipídios em rações para ruminantes. Viçosa, MG: UFV, 1980. 98p. Tese (Doutorado em Zootecnia) - Universidade Federal de Viçosa, 1980.

WILLIAMS, C.H., DAVID, D.J., ILSMAA, O. 1962. The determination chromic oxide in faeces samples by atomic absorption spectrophotometry. J. Anim. Sci., 59(1):391.

Recebido em: 29/05/00

Aceito em: 21/12/00 